\title{
Anaerobic detoxification of acetic acid in a thermophilic ethanologen
}

\author{
A Joe Shaw ${ }^{1,2}$, Bethany B Miller ${ }^{1}$, Stephen R Rogers ${ }^{1}$, William R Kenealy ${ }^{1,3}$, Alex Meola ${ }^{1}$, Ashwini Bhandiwad ${ }^{4,5}$, \\ W Ryan Sillers ${ }^{1,6}$, Indraneel Shikhare ${ }^{1}$, David A Hogsett ${ }^{1,7}$ and Christopher D Herring ${ }^{1,4^{*}}$
}

\begin{abstract}
Background: The liberation of acetate from hemicellulose negatively impacts fermentations of cellulosic biomass, limiting the concentrations of substrate that can be effectively processed. Solvent-producing bacteria have the capacity to convert acetate to the less toxic product acetone, but to the best of our knowledge, this trait has not been transferred to an organism that produces ethanol at high yield.

Results: We have engineered a five-step metabolic pathway to convert acetic acid to acetone in the thermophilic anaerobe Thermoanaerobacterium saccharolyticum. The first steps of the pathway, a reversible conversion of acetate to acetyl-CoA, are catalyzed by the native T. saccharolyticum enzymes acetate kinase and phosphotransacetylase. ack and pta normally divert 30\% of catabolic carbon flux to acetic acid; however, their re-introduction in evolved ethanologen strains resulted in virtually no acetic acid production. Conversion between acetic acid and acetyl-CoA remained active, as evidenced by rapid ${ }^{13} \mathrm{C}$ label transfer from exogenous acetate to ethanol. Genomic re-sequencing of six independently evolved ethanologen strains showed convergent mutations in the hfs hydrogenase gene cluster, which when transferred to wildtype T. saccharolyticum conferred a low acid production phenotype. Thus, the mutated hfs genes effectively separate acetic acid production and consumption from central metabolism, despite their intersecting at the common intermediate acetyl-CoA. To drive acetic acid conversion to a less inhibitory product, the enzymes thiolase, acetoacetate:acetate CoA-transferase, and acetoacetate decarboxylase were assembled in T. saccharolyticum with genes from thermophilic donor organisms that do not natively produce acetone. The resultant strain converted acetic acid to acetone and ethanol while maintaining a metabolic yield of $0.50 \mathrm{~g}$ ethanol per gram carbohydrate.

Conclusions: Conversion of acetic acid to acetone results in improved ethanol productivity and titer and is an attractive low-cost solution to acetic acid inhibition.
\end{abstract}

Keywords: Acetate detoxification, Cellulosic ethanol, Metabolic engineering, Inhibitors

\section{Background}

Biological conversion of low-cost carbohydrate-based renewable resources [1] is often hindered by inhibitors present in these heterogeneous materials. Acetic acid has consistently been reported as one of the most significant inhibitors, followed by furfural, hydroxymethylfurfural, and phenolic compounds [2,3]. Unlike other inhibitors, which are by-products of specific chemical and physical pretreatment processes $[4,5]$, acetic acid can result directly from acetylated carbohydrates, and its production is unavoidable during carbohydrate fermentation.

\footnotetext{
* Correspondence: chrisherringfish@gmail.com

${ }^{1}$ Mascoma Corporation, Lebanon, NH 03766, USA

${ }^{4}$ Thayer School of Engineering, Dartmouth College, Hanover, NH 03755, USA Full list of author information is available at the end of the article
}

Acetic acid is a particularly potent inhibitor at $\mathrm{pH}$ values under 6 , a range common for industrial fermentation [6-8]. Undissociated acetic acid (pKa 4.75) freely passes through cellular membranes, where it can then reach a new equilibrium with dissociated acetic acid at the intracellular $\mathrm{pH}$. The net result is both uncoupling of the transmembrane $\mathrm{pH}$ gradient and an accumulation of acetate anion in the cytoplasm $[9,10]$.

Several chemical and physical methods to separate or detoxify acetic acid prior to fermentation have been proposed [11], but they require additional expense to implement, which may hinder commercial application. Biological removal of acetate has also been proposed via aerobic respiration of acetate followed by fermentation of carbohydrates to ethanol $[12,13]$. However, this requires a separate oxygen- 
dependent incubation, which raises overall process costs. Solventogenic clostridia, typified by Clostridium acetobutylicum, have the native ability to convert acetic acid and butyric acid into the solvents acetone and butanol [14]. The conversion is not easily transferrable to the context of ethanol production though, as it normally occurs in two phases with acetate first produced in an acidogenic phase, followed by conversion to acetone in a solventogenic phase [15].

Acetate detoxification can occur under normal fermentation conditions, enabled by an advanced organism without requiring additional capital equipment. We report conversion of acetic acid to acetone while maintaining a high yield of carbohydrates to ethanol in Thermoanaerobacterium saccharolyticum, thereby demonstrating a low-cost solution to acetic acid inhibition.

\section{Results}

Re-introduction of ack and pta do not restore acetate production in evolved ethanologen strains

T. saccharolyticum has previously been engineered to produce ethanol at high yield by deletion of $l d h$ encoding Llactate dehydrogenase and $a c k$ and $p t a$ encoding acetate kinase and phosphotransacetylase [16,17]. From a carbonbased perspective, these two deletions eliminate organic acid production and force central metabolic flux towards ethanol. From an electron-based perspective, nicotinamide adenine dinucleotide (NADH) generated during glycolysis and reduced ferredoxin generated during pyruvate cleavage must be re-oxidized through reduction of acetyl-CoA to ethanol, rather than through formation of lactic acid or molecular hydrogen (Figure 1). In attempts to engineer ethanologen strains with improved properties for industrial fermentation, we developed multiple strain lineages derived from strain M0355, a $\Delta l d h \Delta a c k \Delta p t a$ mutant [16]. Several of these lineages underwent evolutionary selection, either via continuous culture or serial transfer, for improved fermentation fitness (Figure 2). Interestingly, we found on several occasions that re-introduction of phosphotransacetylase and acetate kinase into evolved strains resulted in greatly reduced acetic acid production as compared to the same genes re-introduced into strain M0355 or the wildtype strain.

\section{Spontaneous mutations occurring during evolutionary selection direct electron flux to ethanol}

One possible explanation for this phenomenon was that mutations which occurred during the evolutionary process direct metabolic flux to ethanol even in the presence of a functional pathway from acetyl-CoA to acetic acid. We re-sequenced the genomes of six evolved strains (Table 1), revealing 12 to 28 mutations per strain. In strains sharing a common lineage, up to 10 of the mutations were present in both strains. However regardless of lineage, we found recurrent mutations in two loci relevant to acetic acid and ethanol production; in subunits of the $h f s$ hydrogenase gene operon and in $a d h E$, the bifunctional acetaldehyde alcohol dehydrogenase (Table 2). We thought either of these mutant loci might contribute to the acetate minus phenomenon; entire deletion of the $h f s$ hydrogenase gene operon has previously been shown to reduce acetic acid production [18], while mutations in adhE could result in a higher affinity for acetyl-CoA or $\mathrm{NAD}(\mathrm{P}) \mathrm{H}$, effectively out-competing acetic acid or hydrogen formation, respectively. To test these possibilities, we introduced the $h f s$ and $a d h E$ mutations that had occurred in evolved strain M0863 into the wildtype background via homologous recombination with selection based on insertion of a kanamycin resistance marker $3^{\prime}$ to the genomic region of interest. Depending on the exact site of recombination crossover, the mutations were not always carried along with the marker. Strains with the desired mutation were identified by DNA sequencing, and strains without mutations were also evaluated to determine effects that introduction of the resistance marker may have introduced. Results are shown in Table 3. While the mutant adhE gene had an impact on end product ratios, only the strain carrying the $h f s$ spontaneous mutations produced significantly less acetic acid, with a combined ethanol and lactate to acetate ratio 10-fold higher than wildtype. Introduction of the M0863-acquired $h f s$ mutations did not appear detrimental to growth rate, which was in contrast to a complete deletion of the $h f s$ operon, which decreased growth rate and the amount of consumed carbohydrate [18].

\section{Acetic acid and acetyl-CoA freely interconvert in evolved ethanologen strains harboring ack and pta}

Figure 3 shows ${ }^{13} \mathrm{C}_{2}$-labeled acetate spiked at 18 hours in a batch carbohydrate fermentation with strain M1667 (an evolved ethanologen from the M0863 lineage with reintroduced ack and pta genes) in the presence of $60 \mathrm{mM}$ externally added acetic acid. Based on nuclear magnetic resonance (NMR) spectra, the ${ }^{13} \mathrm{C}_{2}$ label is almost completely transferred from acetic acid to ethanol within 7 hours, despite minimal change in the bulk acetic acid concentration. This data indicates a dilution of the ${ }^{13} \mathrm{C}_{2}$ acetate pool by approximately $50 \%$ in an hour and a corresponding increase in ${ }^{13} \mathrm{C}_{2}$ ethanol. No other metabolite showed enrichment of ${ }^{13} \mathrm{C}$ beyond that expected from natural abundance indicating that the acetate was metabolized intact. In similar experiments with strain M1291, the direct parent strain of M1667 without ack and pta, there was no evidence of ${ }^{13} \mathrm{C}$ label transfer from acetic acid for up to 48 hours after spike addition.

The reaction acetic acid $+\mathrm{ATP}+\mathrm{CoA} \leftrightarrow$ acetyl-CoA + $\mathrm{ADP}+\mathrm{P}_{\mathrm{i}}$ is near thermodynamic equilibrium $(+2 \mathrm{~kJ} / \mathrm{mol}$ at $\mathrm{pH}$ 7) and is used by microorganisms for both acetate production and consumption in various environmental 


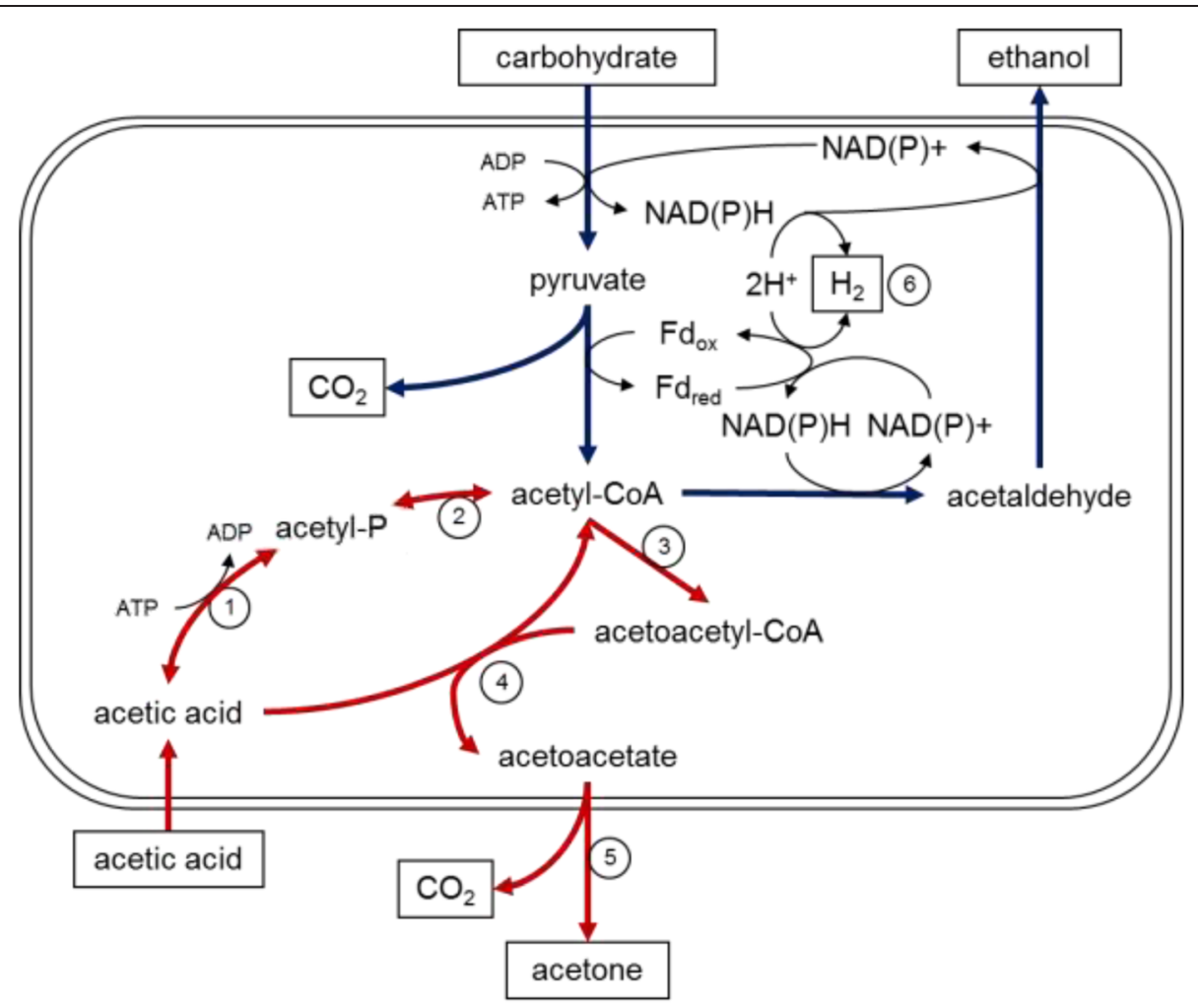

Figure 1 Synthetic pathway to convert acetic acid to acetone. Acetic acid diffuses freely into the cell following hydrolysis of acetylated polysaccharides and is then activated to acetyl-CoA by acetate kinase (1), phosphotransacetylase (2), and a half-reaction of CoA-transferase (4). Two acetyl-CoA molecules are then converted to acetoacetyl-CoA by thiolase (3), acetoacetate by the other half-reaction of $\mathrm{CoA}$-transferase, and finally to acetone and $\mathrm{CO}_{2}$ by acetoacetate decarboxylase (5). Although the synthetic pathway shares a common intermediate with the ethanol production pathway, carbohydrate to ethanol production remains highly coupled due to the requirement to balance $\mathrm{NAD}(\mathrm{P})+\mathrm{NAD}(\mathrm{P}) \mathrm{H}$ generation. Hydrogenases (6) act to uncouple electron acceptor regeneration and ethanol formation, resulting in production of acetic acid through the reversible acetate kinase and phosphotransacetylase pathway.

conditions [19-22]. Although the bulk concentration of acetic acid remained constant in evolved ethanologen strains containing $p t a$ and $a c k$, we hypothesize that labeled acetate is reversibly converted into labeled acetyl$\mathrm{CoA}$, a fraction of which is then irreversibly converted into labeled ethanol. The intracellular acetyl-CoA pool is also fed by unlabeled carbohydrate metabolism and, assuming that ${ }^{13} \mathrm{C}$ label is not differentially recognized, can be equally used to produce acetate or ethanol. Carbohydratederived acetyl-CoA then acts to dilute the labeled acetate/ acetyl-CoA pool and allows the creation of labeled ethanol. Due to stoichiometric coupling with hydrogen formation,

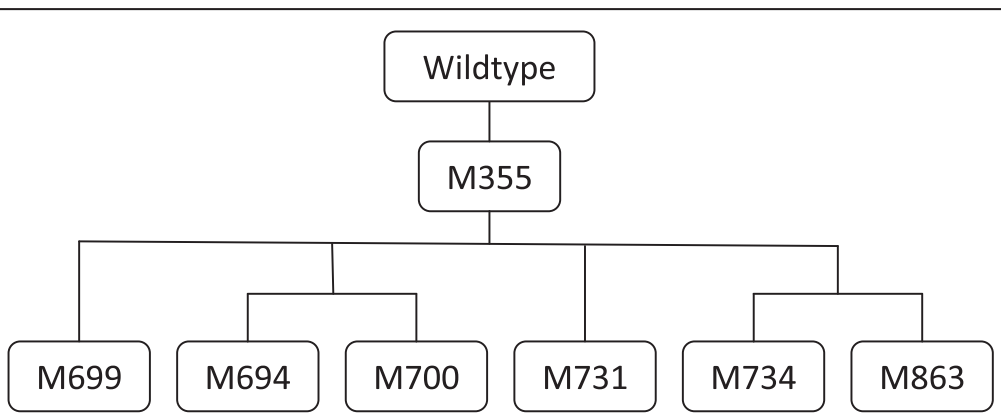

Figure 2 Lineage of strains selected for improved growth rate and ethanol production in this study. M0355 carries deletions of the Idh, pta, and ack but was not selected for improved growth rate. The lineages resulting in M0694, M0699, and M0700 were cultivated in continuous culture to select for improved growth properties. The lineages resulting in M0731, M0734, and M0863 were exposed to chemical mutagenesis and serial transfer for improved growth properties; the lineage resulting in M0863 was subsequently cultured in continuous culture. All strains were isolated as single colonies prior to genomic DNA isolation and re-sequencing. 
Table 1 Strains used in this study

\begin{tabular}{|c|c|c|}
\hline Strain & Description & Source \\
\hline M0010 & T. saccharolyticum JW/SL-YS485 DSM 8691 & DSMZ \\
\hline M0355 & T. saccharolyticum $\Delta p t a \Delta a c k \Delta / d h$ & (16) \\
\hline M1291 & T. saccharolyticum $\triangle p t a \triangle a c k \triangle l d h$ Cth ureABCDEFG & This study \\
\hline M1442 & T. saccharolyticum $\triangle p t a \triangle a c k \triangle l d h$ Cth ureABCDEFG & This study \\
\hline M1667 & T. saccharolyticum $\triangle$ pta $\triangle a c k \Delta l d h::$ Tsa pta ack kanR Cth ureABCDEFG & This study \\
\hline M2030 & $\begin{array}{l}\text { T. saccharolyticum } \triangle \text { pta } \triangle a c k \Delta l d h:: \text { Tsa pta ack Cac thl Tme thl Tte thl } \\
\text { Cac ctfAB Tme ctfAB Cac adc Bam adc kanR Cth ureABCDEFG }\end{array}$ & This study \\
\hline M2202 & T. saccharolyticum adhE*::kanR & This study \\
\hline M2203 & T. saccharolyticum adhE::kanR & This study \\
\hline M2204 & T. saccharolyticum hfs*:.kanR & This study \\
\hline M2205 & T. saccharolyticum hfs.:kanR & This study \\
\hline M2212 & T. saccharolyticum $\triangle$ pta $\triangle a c k \triangle l d h:: T s a$ pta ack Tte thl Tme ctfAB Bam adc kanR Cth ureABCDEFG & This study \\
\hline Top10 & E. coli cloning strain & Invitrogen, Madison, WI \\
\hline \multirow[t]{2}{*}{ FY2 } & S. cerevisiae cloning strain & (37) \\
\hline & Re-sequenced strains with improved growth rate & \\
\hline M0694 & T. saccharolyticum $\Delta$ pta $\Delta a c k \Delta / d h$ continuous cultured adapted & This study \\
\hline M0699 & T. saccharolyticum $\Delta$ pta $\triangle a c k \Delta l d h$ continuous cultured adapted & This study \\
\hline M0700 & T. saccharolyticum $\Delta$ pta $\Delta a c k \Delta / d h$ continuous cultured adapted & This study \\
\hline M0731 & T. saccharolyticum $\Delta p t a \Delta a c k \Delta / d h$ mutation and serial transfer & This study \\
\hline M0734 & T. saccharolyticum $\Delta p t a \Delta a c k \Delta / d h$ mutation and serial transfer & This study \\
\hline M0863 & T. saccharolyticum $\Delta p t a \Delta a c k \Delta l d h$ mutation and serial transfer & This study \\
\hline
\end{tabular}

DSMZ, Deutsche Sammlung von Mikroorganismen und Zellkulturen.

net acetate formation is arrested via the evolutionarily acquired $h f s$ mutations while the capacity to convert acetate to acetyl-CoA is retained.

\section{Construction of a synthetic pathway for the conversion of acetic acid to acetone}

Exogenously added acetone is substantially less inhibitory than acetic acid to $T$. saccharolyticum in the $\mathrm{pH}$ range of 5.0 to 5.5 relevant to industrial fermentation (Figure 4). Additionally, conversion of two molecules of acetic acid results in one molecule of acetone, further lowering the potential for acetone inhibition. Solventogenic Clostridia such as $C$. acetobutylicum have native biochemical pathways to convert acetic acid into acetone, although they are intricately coupled to carbohydrate metabolism. We began by importing the $C$. acetobutylicum acetone pathway, inclusive of thiolase, acetate:acetoacetylCoA-transferase, and acetoacetate decarboxylase (thl ctfAB $a d c)$ as well as the $T$. saccharolyticum acetate kinase and phosphotransacetylase into the $T$. saccharolyticum expression plasmid pMU1299 that integrates at the ldh locus. Despite conferring acetone production in E. coli (Table 4),

Table 2 Mutations identified by re-sequencing

\begin{tabular}{|c|c|c|c|c|c|}
\hline Gene & Locus tag & ORF nt & DNA mutation & Coding change & Occurrence in strain \\
\hline adhE & Tsac_416 & 1630 & $\mathrm{G} \rightarrow \mathrm{A}$ & $G \rightarrow D$ & M0734, M0863 \\
\hline adhE & Tsac_416 & 1804 & $C \rightarrow T$ & $S \rightarrow L$ & M0699 \\
\hline adhE & Tsac_416 & 1808 & $A \rightarrow G$ & $\mathrm{E} \rightarrow \mathrm{G}$ & M0694, M0700 \\
\hline$h f_{S} A$ & Tsac_1550 & 159 & $A \rightarrow-$ & Frameshift & M0700 \\
\hline$h f_{s} B$ & Tsac_1551 & 434 & $A \rightarrow-$ & Frameshift & M0734, M0863 \\
\hline$h f_{s} B$ & Tsac_1551 & 652 & $A \rightarrow-$ & Frameshift & M0731 \\
\hline$h f_{s} \mathrm{C}$ & Tsac_1552 & 255 & $A \rightarrow-$ & Frameshift & M0699 \\
\hline$h f s D$ & Tsac_1553 & 193 & $\mathrm{G} \rightarrow \mathrm{A}$ & $A \rightarrow T$ & M0699 \\
\hline$h f_{s} D$ & Tsac_1553 & 321 & $A \rightarrow T$ & $\mathrm{R} \rightarrow \mathrm{S}$ & M0863 \\
\hline$h f s D$ & Tsac_1553 & 787 & $\mathrm{G} \rightarrow \mathrm{A}$ & $E \rightarrow K$ & M0734 \\
\hline
\end{tabular}


Table 3 Re-introduction of spontaneous adhE and hfs hydrogenase mutations that occurred during growth adaptation of the $\Delta / d h, \Delta$ pta $\Delta a c k$ ethanologen strain M0863 into wildtype (WT) T. saccharolyticum

\begin{tabular}{|c|c|c|c|c|c|c|}
\hline \multirow[b]{2}{*}{ Strain } & \multirow[b]{2}{*}{ Genotype } & \multicolumn{4}{|l|}{ Units in $\mathrm{mM}$} & \multirow[b]{2}{*}{ Carbon recovery $(\%$} \\
\hline & & Cellobiose consumed & Lactate & Acetate & Ethanol & \\
\hline M0010 & WT & $28.2 \pm 0.6$ & $13.8 \pm 0.5$ & $34.7 \pm 0.7$ & $63.5 \pm 2.3$ & 99 \\
\hline M2202 & $a d h E^{*}: . k a n^{R}$ & $30.2 \pm 0.0$ & $2.4 \pm 0.1$ & $42.3 \pm 0.3$ & $76.5 \pm 0.6$ & 100 \\
\hline M2203 & adhE:::kan ${ }^{R}$ & $27.7 \pm 2.6$ & $1.4 \pm 0.2$ & $29.0 \pm 1.6$ & $78.4 \pm 8.6$ & 98 \\
\hline M2204 & $h f s^{*}:: k a n^{R}$ & $29.9 \pm 0.1$ & $20.3 \pm 0.5$ & $4.2 \pm 0.1$ & $91.7 \pm 0.6$ & 97 \\
\hline M2205 & $h f s .: \mathrm{kan}^{R}$ & $28.1 \pm 0.7$ & $9.9 \pm 2.2$ & $29.8 \pm 1.1$ & $67.9 \pm 2.7$ & 96 \\
\hline
\end{tabular}

${ }^{*}$ mutations found in evolved strain $\mathrm{M} 0863$ introduced by homologous recombination. Data are average of four replicates, anaerobic TSC7 medium, $55^{\circ} \mathrm{C}, 24-\mathrm{h}$ fermentation of $30.4 \pm 0.7 \mathrm{mM}$ cellobiose. Mutations were created via homologous recombination of a kanamycin resistance marker downstream of the $h f s$ operon that contained mutations in the upstream flanking region. M2202 - kan ${ }^{\mathrm{R}}$ inserted $3^{\prime}$ of the adhE gene, with the M0863 mutant adhE sequence. M2203 - kan ${ }^{\mathrm{R}}$ inserted $3^{\prime}$ of the adhE gene, with the WT adhE sequence. M2204 - kan $^{\mathrm{R}}$ inserted $3^{\prime}$ of the $h f$ s gene operon, with the M0863 mutant $h f s$ sequence. M2205 - kan ${ }^{\mathrm{R}}$ inserted $3^{\prime}$ of the hfs gene operon, with the WT hfs sequence.

we could find no evidence of acetone formation upon integration of the plasmid in T. saccharolyticum. While RTPCR experiments (not shown) indicated transcriptional activity of the acetone pathway genes, a likely issue was temperature incompatibility of the donor and host organism; C. acetobutylicum has grown optimally between $30^{\circ} \mathrm{C}$ and $37^{\circ} \mathrm{C}$, while $T$. saccharolyticum's growth rate drops precipitously below $48^{\circ} \mathrm{C}$, the lowest temperature where we assayed for acetone formation.

We next looked for thermophilic acetone producers but could not find a native acetone producer with an optimal growth temperature higher than $43^{\circ} \mathrm{C}$ [23]. We could, however, find homologs to each of the three enzymes in the acetone pathway residing in the sequenced genomes of thermophilic bacteria (Table 5). None of these thermophiles were reported to produce acetone, and the entire pathway was not present in a single organism. To explore the ability of these genes to produce acetone, we opted to progressively incorporate expression vectors harboring thermophilic acetone pathway homologs into T. saccharolyticum and assay the resulting strains for acetone production. Qualitative evidence of ketone body formation was first identified in strain M2030 (Figure 5), which contained, in addition to the T. saccharolyticum ack and pta genes, three thl genes, two $c t f A B$ gene operons, and two $a d c$ genes. We then constructed strains with minimal sets of acetone pathway genes while continuing to assay for acetone formation; the most efficient acetone producer, M2212, was created by expression of a putative thiolase from Thermoanaerobacterium thermosaccharolyticum DSM 571, a putative CoA-transferase from Thermosipho melanesiensis DSM 12029, and a putative acetoacetate
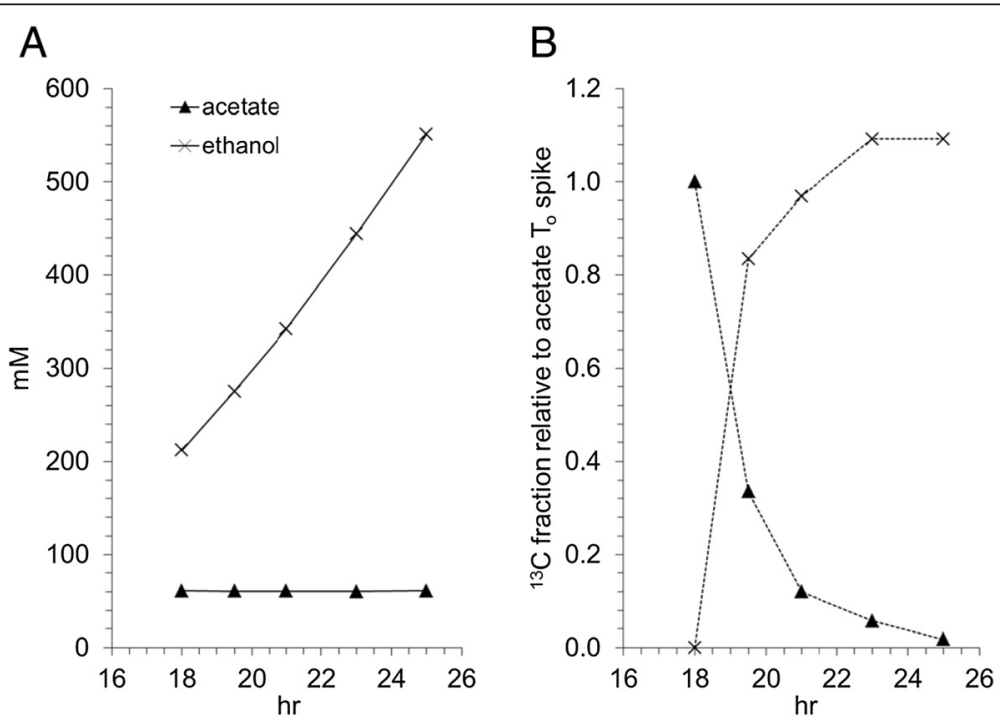

Figure 3 Fate of ${ }^{13} \mathrm{C}_{2}$-labeled acetate during strain M1667 carbohydrate fermentation. Strain M1667 was grown in batch fermentation in a 3:2 weight mixture of maltodextrin and cellobiose at a concentration of $900 \mathrm{mM}$ glucose equivalents and $45 \mathrm{mM}$ acetic acid at an initial pH of 6.0. At 18 hours, the culture was spiked with $15 \mathrm{mM}$ sodium acetate $-^{13} \mathrm{C}_{2}$. Bulk metabolite measurements (A) and ${ }^{13} \mathrm{C}$ label (B) were monitored for extracellular acetic acid (filled triangles) and ethanol (crosses). No appreciable label was found in metabolites other than acetic acid and ethanol. Data is from one representative experiment. 


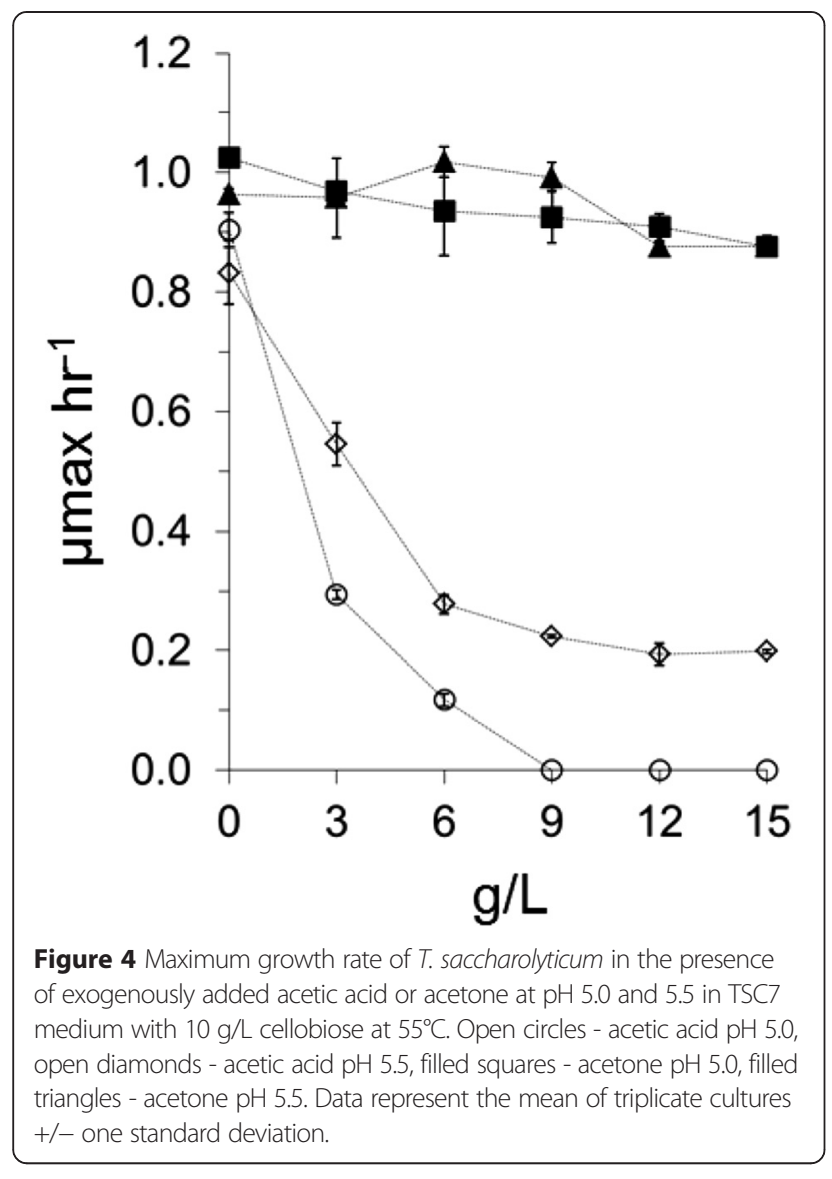

decarboxylase from Bacillus amyloliquefaciens FZB42. The T. thermosaccharolyticum thl is part of a gene operon with several homologs involved in butanol production, and the organism has been reported to produce butanol [24]. $T$. melanesiensis ctfAB is adjacent to a thiolase in its native genetic organization, which could potentially be involved in acetoacetate degradation. The B. amyloliquefaciens adc appears to be independently transcribed; however, the native function of either enzyme is not obvious based on genetic organization and the known physiology of these organisms.

Strain M2212 was also assayed for the in vitro ability to catalyze conversions along the pathway of acetyl-CoA to acetone. Table 6 shows data collected from cell-free extract measurements of thiolase, CoA-transferase, and acetoacetate

Table 4 Acetone production in E.coli

\begin{tabular}{llllll}
\hline & Glucose & Lactic & Acetic & Ethanol & Acetone \\
\hline Media & 24.5 & 0.0 & 4.2 & 0.0 & 0.0 \\
TOP10 + pMU1299 & 16.1 & 5.9 & 3.1 & 0.5 & 1.8 \\
TOP10 + pACYC177 & 19.5 & 3.6 & 5.1 & 0.4 & 0.0 \\
\hline
\end{tabular}

Fermentation end point at 170 hours, in LB media supplemented with $25 \mathrm{~g} / \mathrm{L}$ glucose, $4 \mathrm{~g} / \mathrm{L}$ acetic acid, and $50 \mu \mathrm{g} / \mathrm{mL}$ kanamycin sulfate. Microaerobic conditions were utilized by inoculation into sealed $125 \mathrm{~mL}$ pressure bottles with atmospheric pressure air. Incubation was performed without agitation at $30^{\circ} \mathrm{C}$, with a $1 / 10^{\text {th }} \mathrm{v} / \mathrm{v}$ inoculation from aerobically grown overnight LB media supplemented with kanamycin. decarboxylase from strain M2212 and M1442, the direct parent ethanologen. While activities for these enzymes were at or below the limit of detection with strain M1442, detectable levels were found for each step with strain M2212.

Expression of the synthetic acetone pathway improves ethanol productivity and titer in the presence of acetic acid Strain M2212 and strain M1442 were grown in batch fermentation in the presence of acetic acid (Figure 6). M2212 reduced the overall acetic acid concentration by $2.8 \mathrm{~g} / \mathrm{L}$, which in combination with an increase in the $\mathrm{pH}$, reduced the undissociated acetic acid concentration from an initial $1.3 \mathrm{~g} / \mathrm{L}$ to below $0.6 \mathrm{~g} / \mathrm{L} .0 .78 \mathrm{~g} / \mathrm{L}$ acetone was produced, a value lower than that expected from the theoretical $0.5 \mathrm{~g} / \mathrm{g}$ conversion of acetic acid to acetone. However, this measurement may also reflect some acetone evaporation during fermentation gas release, as the boiling point of acetone, $54^{\circ} \mathrm{C}$, is slightly below the $55^{\circ} \mathrm{C}$ fermentation temperature. In contrast, fermentation with strain M1442 resulted in a small $0.4 \mathrm{~g} / \mathrm{L}$ increase in acetic acid, while the undissociated acetic acid concentration rose to over $4.3 \mathrm{~g} / \mathrm{L}$ as a result of declining $\mathrm{pH}$ during the fermentation. From Figure 4, a 50\% decrease in $\mu \max$ occurs at an undissociated acetic acid concentration of 0.61 to $0.81 \mathrm{~g} / \mathrm{L}$. The decline in $\mathrm{pH}$ with strain M1442 is likely a result of assimilation of ammonium sulfate and carbonic acid generated during production of carbon dioxide. The conversion of acetic acid to acetone completely reversed this $\mathrm{pH}$ trend in strain M2212.

Strain M2212 has favorable ethanol fermentation metrics as well; compared to M1442, the final ethanol titer was $33.1 \mathrm{~g} / \mathrm{L}$ higher, an increase of more than $300 \%$. Volumetric productivity at 48 hours rose from $0.22 \mathrm{~g} / \mathrm{L} \mathrm{hr}^{-1}$ to $0.92 \mathrm{~g} / \mathrm{L} \mathrm{hr}^{-1}$, also an increase of over $300 \%$. Final metabolic yields, as a measure of gram ethanol produced per gram glucose equivalent consumed, were $0.48 \mathrm{~g} / \mathrm{g}$ for M1442 and $0.50 \mathrm{~g} / \mathrm{g}$ for M2212.

\section{Discussion}

The observation that re-introduction of $a c k$ and $p t a$ in evolved ethanologen strains resulted only in minute amounts of acetic acid production was surprising; the genes had initially been removed to eliminate acetic acid production, which can account for up to $30 \%$ of total organic end products on a molar basis in wildtype cells $[17,25]$. Predicting that evolutionary selection had imparted mutations resulting in this phenotype, we examined the genome sequences of several strains descended from strain M0355 that had been serially or continuously cultured for several generations. We identified two mutational hotspots, in the $h f s$ hydrogenase gene operon and the $a d h E$ bifunctional acetaldehyde/alcohol dehydrogenase, that could be rationally predicted to impact acetic acid production. 
Table 5 Genes tested for acetone production in T.saccharolyticum

\begin{tabular}{|c|c|c|c|}
\hline Source strain & $\mathrm{T}_{\text {opt }}\left({ }^{\circ} \mathrm{C}\right)$ & Gene & Genbank protein \\
\hline Thermoanaerobacterium saccharolyticum DSM 8691 & 60 & pta & ACA51668 \\
\hline Thermoanaerobacterium saccharolyticum DSM 8691 & 60 & ack & ACA51669 \\
\hline Clostridium acetobutylicum ATCC 824 & 35 & thl & NP_349476 \\
\hline Thermosipho melanesiensis DSM 12029 & 70 & thl & YP_001306374 \\
\hline Kosmotoga olearia DSM 21960 & 65 & thl & YP_002940320 \\
\hline Thermoanaerobacterium thermosaccharolyticum DSM 571 & 60 & thl & YP_003852249 \\
\hline Thermoanaerobacterium thermosaccharolyticum DSM 571 & 60 & $a c t A$ & CAA93155 \\
\hline Clostridium acetobutylicum ATCC 824 & 35 & $C t f A$ & NP_149326 \\
\hline Thermosipho melanesiensis DSM 12029 & 70 & $C t f A$ & YP_001306376 \\
\hline Kosmotoga olearia DSM 21960 & 65 & $C t f A$ & YP_002940319 \\
\hline Clostridium acetobutylicum ATCC 824 & 35 & $C t f B$ & NP_149327 \\
\hline Thermosipho melanesiensis DSM 12029 & 70 & $C t f B$ & YP_001306375 \\
\hline Kosmotoga olearia DSM 21960 & 65 & $C t f B$ & YP_002940318 \\
\hline Clostridium acetobutylicum ATCC 824 & 35 & adc & NP_149328 \\
\hline Acidothermus cellulolyticus B11 ATCC 43068 & 55 & $a d c$ & YP_872855 \\
\hline Bacillus amyloliquefaciens FZB42 BGSC 10 A6 & 50 & adc & YP_001422565 \\
\hline
\end{tabular}

$\mathrm{T}_{\mathrm{opt}}$ is the optimal temperature for growth of the source strain.

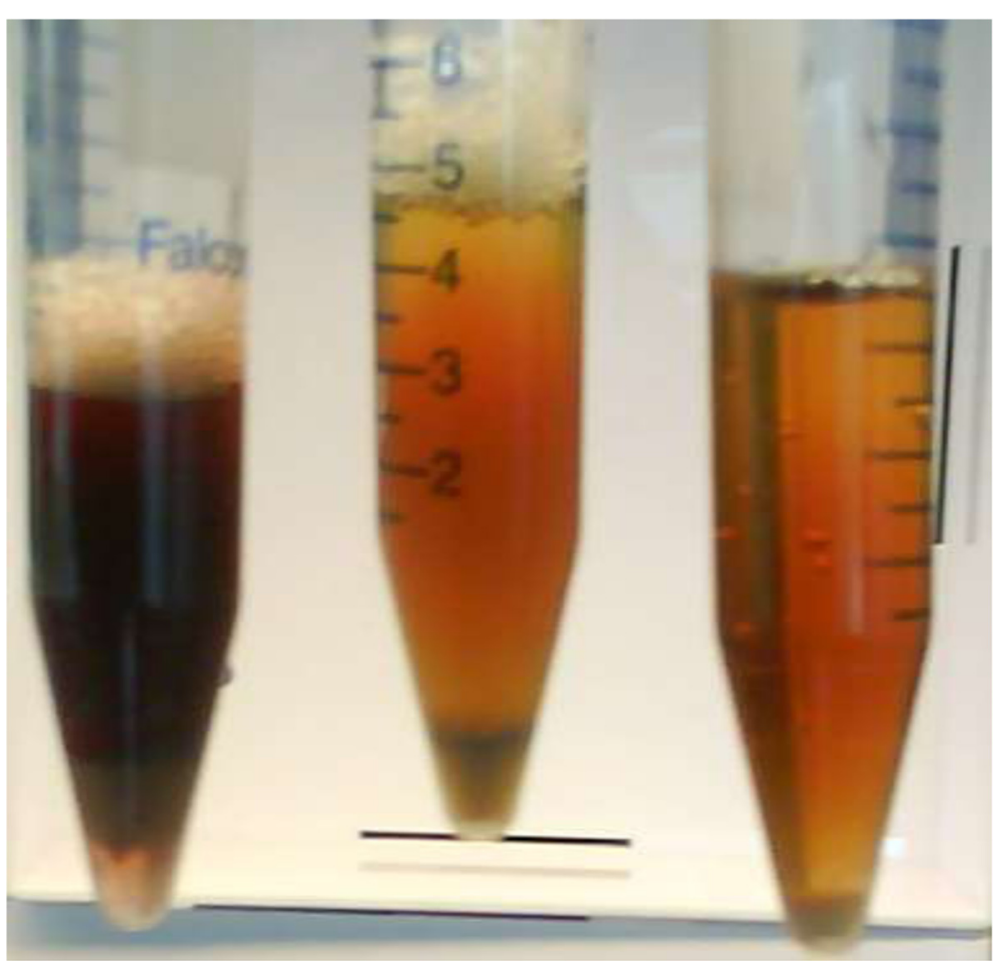

Figure 5 Rothera's test (1) for acetone and acetoacetic acid formation performed on spent fermentation medium, initially containing $50 \mathrm{~g} / \mathrm{L}$ cellobiose and $5 \mathrm{~g} / \mathrm{L}$ acetic acid. From left to right, M2030, M1675 + pMU131 (the immediate parent strain of M2030), and uninoculated medium. Acetone and acetoacetic acid are characterized by a purple/red coloremetric reaction with sodium nitroprusside in the presence of saturating ammonia. To perform the test, 4-mL samples were saturated with ammonium sulfate, and 5\% sodium nitroprusside was added followed by an overlay of $1 \mathrm{~mL}$ 25\% ammonium hydroxide. Photograph was taken 18 hours after addition of sodium nitroprusside. 
Table 6 Enzymatic activities in cell extracts

\begin{tabular}{lllllll}
\hline \multicolumn{1}{c}{} & $\boldsymbol{\mu}$ mol $\mathbf{~ m i n}^{-\mathbf{1}} \mathbf{~ m}^{-\mathbf{1}}$ protein & & & & \\
\cline { 2 - 7 } & Thiolase & SD & CoA-transferase & SD & Acetoacetate decarboxylase & SD \\
\hline M1442 & 0.06 & 0.13 & 0.02 & 0.02 & 0.17 & 0.23 \\
M2212 & 10.21 & 0.55 & 3.57 & 0.09 & 1.66 & 0.26 \\
\hline
\end{tabular}

Data represent the mean of triplicate determinations +/- one standard deviation. SD, standard deviation.

Introducing these mutations to the wildtype strain indicated that the $h f s$ mutation is responsible for a sharp decrease in acetic acid production.

An entire deletion of the $h f s$ operon has previously been shown to reduce acetic acid production in wildtype and $\Delta l d h \quad T$. saccharolyticum strains [18]. However, it also results in strains with poor fermentation kinetics, which are not readily improved after several serial transfers. Deletion of the entire $h f s$ operon in evolved $\Delta l d h$ sack $\Delta p t a$ ethanologens also resulted in strains with poor fermentation kinetics, suggesting that the point mutations acquired through evolution have a more nuanced effect than an entire loss of function mutation. Any fitness advantage the $h f s$ mutations impart to ethanologen strains is unknown, although it is tempting to speculate that cellular redox regulation may play a role. Of six evolved strains, five acquired frameshift mutations in the genes $h f_{s} A, h f_{s} B$, or $h f_{s} C$, encoding a putative

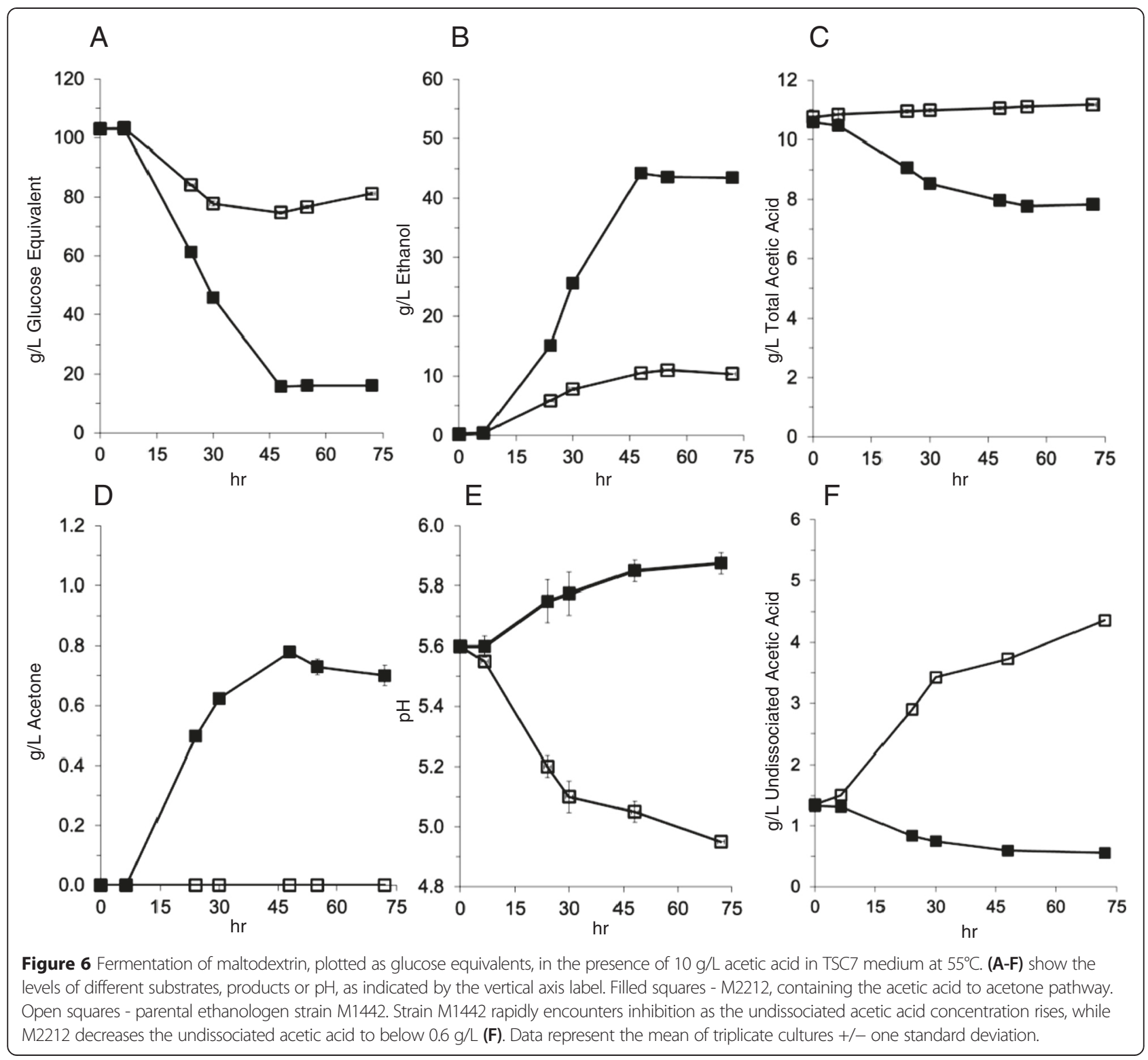


ferredoxin, a hydrogenase and [PAS] sensory domain fusion and a histidine kinase, respectively. Identification and classification of $[\mathrm{FeFe}]$ hydrogenases with possible sensory functions is an area of current investigation [26-28]. These frameshift mutations may be beneficial by loss of function of the affected gene but may also have beneficial effects through polar down-regulation of the gene $h f s D$ downstream. This gene, encoding a putative monomeric group $\mathrm{B}$ [FeFe] hydrogenase [28], only acquired point mutations, resulting in amino acid changes in three of six strains. A small amount of hydrogen production can be predicted to be important for ethanologen strains to maintain redox balance with cell mass and associated carbon dioxide generation from carbohydrates, in a role parallel to that of glycerol formation in S. cerevisiae [29-31].

The adhE mutations, although not further investigated here, may be involved in co-factor specificity and increased ethanol tolerance, as previously reported for $C$. thermocellum [32]. Another evolved T. saccharolyticum ethanologen, strain ALK2, was shown to have an increase in nicotinamide adenine dinucleotide phosphate (NADPH) specificity and a decrease in NADH specificity for whole cell extract alcohol dehydrogenase activity [17].

The combination of $h f s$ gene mutations and $a c k$ and pta re-introduction allows for inter-conversion of acetic acid and acetyl-CoA independent of central metabolism. To detoxify acetic acid with concurrent high yield fermentation of carbohydrates to ethanol, the solvent acetone was an attractive end product of acetic acid metabolism. It is less inhibitory than acetic acid, can be easily recovered through distillation, and can be sold as a commodity chemical. The native solventogenic clostridial pathway takes one acetyl-CoA and one acetic acid and converts them to one $\mathrm{CoA}$, one $\mathrm{CO}_{2}$, and one acetone. This, combined with action of phosphotransacetylase and acetate kinase, allows the redox neutral conversion of two acetic acid and one ATP to one acetone, one $\mathrm{CO}_{2}$, one $\mathrm{H}_{2} \mathrm{O}$, and one ADP $+\mathrm{P}_{\mathrm{i}}$. The standard Gibbs free energy change for this reaction is $-0.8 \mathrm{~kJ} / \mathrm{rxn}$, a fairly small driving force. However, if acetic acid accumulates intracellularly due to a transmembrane $\mathrm{pH}$ gradient, the overall reaction will become increasingly thermodynamically favorable. Assuming acetic acid is at intracellular and extracellular equilibrium, an extracellular change of $1.0 \mathrm{pH}$ unit more acidic results in a $\Delta G^{\prime}$ change of $-12.4 \mathrm{~kJ} / \mathrm{rxn}$. Thus, the pathway becomes more thermodynamically feasible as acetic acid becomes more inhibitory.

The inability to produce acetone in $T$. saccharolyticum with heterologously expressed enzymes from $C$. acetobutylicum and the lack of natively thermophilic acetone producers led us to test homologs of thiolase, CoAtransferase, and acetoacetate decarboxylase from thermophiles that presumably participate in other metabolic pathways. The final pathway reported here, utilizing genes from $T$. saccharolyticum, $T$. thermosaccharolyticum, $T$. melanesiensis, and B. amyloliquefaciens, is assembled entirely from organisms that do not produce acetone from acetic acid.

Despite being carbon and electron independent, production of acetone from acetic acid does require chemical energy in the form of ATP, which must be supplied from central catabolism. Based on a stoichiometric evaluation of the fermentation presented in Figure 6, 5\% of the total ATP produced by carbohydrate catabolism is used for acetic acid conversion to acetone during the maximum rate of acetone formation. The rapid and complete conversion of ${ }^{13} \mathrm{C}$-labeled acetate to ethanol indicates there is sufficient capacity for acetate entry into the cell. Further conversion could be limited by thermodynamic feasibility, as the majority of the residual acetic acid is in the dissociated species when the rate of acetone production decreases.

From economic and process engineering perspectives, biological conversion of acetic acid to acetone provides several distinct advantages over other detoxification methods. In the case of lignocellulose to ethanol conversion, it is likely to increase ethanol productivity and titer, while maintaining the carbohydrate to ethanol yield essential for efficient biofuel production. Acetone is readily recovered by distillation equipment already installed for ethanol recovery, and it has a selling price around $\$ 1.15$ per kg [33] with a North American market size of 1.6 MM metric tons per year [34]. The conversion of acetic acid to a solvent reduces the demand for $\mathrm{pH}$ neutralization during fermentation and lowers the chemical or biological oxygen demand for wastewater treatment during water recycle, as acetic acid composes half or more of soluble, unrecovered organic material in a typical lignocellulose process [35]. Finally, unlike chemical or physical methods to remove acetic acid, conversion to acetone does not require significant additional capital or operating expenditures, as new unit operations are not required beyond separation of acetone from ethanol. With these factors taken together, this technology has the potential to lower costs and improve the feasibility of large scale, anaerobic production of biofuels and biochemicals from acetate containing feedstocks.

\section{Conclusions}

Spontaneous mutations acquired in the $h f s$ hydrogenase gene cluster prevent net acetate production in strains in which the pta and ack genes are re-introduced. Surprisingly, uptake and incorporation of exogenous acetate occurs in those strains even when overall acetate levels remain constant, as shown by ${ }^{13} \mathrm{C}$-labeling. Genes from C. acetobutylicum did not confer a functional acetone production pathway, but genes assembled from a variety of thermophilic species did. The best performing strain converted exogenous acetate to acetone, while markedly improving 
ethanol production. These findings improve our understanding of acetate and ethanol metabolism and demonstrate a novel strategy for converting a potential inhibitor into a valuable co-product.

\section{Methods}

\section{Strains and DNA vectors}

Strains used in this study are listed in Table 1, and plasmids and primers are given in Additional file 1. Plasmids used to transform T. saccharolyticum were constructed with S. cerevisiae gap repair cloning techniques and amplified in E. coli [36]. T. saccharolyticum was transformed using a natural competence based system [37], and transformants were selected by resistance to the antibiotic kanamycin. Chromosomal integrants were evaluated by colony PCR with primers which hybridized to regions external and internal to the integration region.

\section{Fermentation conditions}

T. saccharolyticum was primarily grown in modified TSC7 medium, containing per liter $1.0 \mathrm{~g}$ sodium citrate tribasic dihydrate, $4.0 \mathrm{~g}\left(\mathrm{NH}_{4}\right)_{2} \mathrm{SO}_{4}, 0.2 \mathrm{~g} \mathrm{FeSO}_{4} \cdot 7 \mathrm{H}_{2} \mathrm{O}, 2.0 \mathrm{~g}$ $\mathrm{MgSO}_{4} \cdot 7 \mathrm{H}_{2} \mathrm{O}, 1.0 \mathrm{~g} \mathrm{KH}_{2} \mathrm{PO}_{4}, 0.2 \mathrm{~g} \mathrm{CaCl}_{2} \cdot 2 \mathrm{H}_{2} \mathrm{O}, 0.12 \mathrm{~g} \mathrm{~L}-$ methionine, $0.5 \mathrm{~g}$ L-cystiene $\mathrm{HCl}$, and $8.5 \mathrm{~g}$ yeast extract. For $\mathrm{C}^{13}$ acetate labeling experiments, TSC4 base medium was used, with the following differences from TSC7: $5 \mathrm{~g}$ urea replacing $\left(\mathrm{NH}_{4}\right)_{2} \mathrm{SO}_{4}, 0.5 \mathrm{~g} \mathrm{MgSO}_{4} \cdot 7 \mathrm{H}_{2} \mathrm{O}, 0.5 \mathrm{~g}$ $\mathrm{KH}_{2} \mathrm{PO}_{4}$, and $2 \mathrm{~g}$ sodium citrate tribasic dihydrate. Carbohydrates and acetic acid were added as indicated in the text and figure legends. Chemicals, including ${ }^{13} \mathrm{C}_{2}$ acetate, were acquired from Sigma-Aldrich (St Louis, MO, USA). Fermentations were begun by addition of $10 \% v / v$ from an exponentially growing pre-culture and were performed in sealed pressure vessels $(120-\mathrm{mL}$ bottles with a $20-\mathrm{mL}$ working volume for high carbohydrate concentrations and 20-mL tubes with a 5-mL working volume for low carbohydrate concentrations. Vessels were purged with an anaerobic gas mixture containing $95 \% \mathrm{~N}_{2}$ and $5 \% \mathrm{CO}_{2}$ and vented to atmospheric pressure at each sampling. Fermentations were performed at $55^{\circ} \mathrm{C}$ and shaking at 150 to $200 \mathrm{rpm}$.

\section{Analytical methods}

Fermentation metabolite concentrations were determined by high-performance liquid chromatography (HPLC) using an Aminex HPX-87H column (Bio-Rad Laboratories, Hercules, CA, USA) with a refractive index detector. Acetone was additionally identified with a UV detector at $260 \mathrm{~nm}$. Proton-decoupled one-dimensional ${ }^{13} \mathrm{C}$ spectra were obtained from fermentation samples mixed with $\mathrm{D}_{2} \mathrm{O}(20 \%)$ with a Varian Inova $500 \mathrm{MHz}$ NMR spectrometer (Bloomington, IN, USA) operating at $125 \mathrm{MHz}$ using the WALTZ-16 sequence for decoupling. The sweep width was $18 \mathrm{kHz}$, and acquisition time was $1.5 \mathrm{~s}$. A pulse angle of $80^{\circ}$ and $0.8 \mathrm{~s}$ delay were used. Data $(65,000 \mathrm{pts})$ was Fourier transformed with a line broadening of $0.5 \mathrm{~Hz}$.

Ketone body formation was qualitatively assayed via the Rothera method, as described in Figure 5. Maltodextrin was hydrolyzed with $A$. niger amyloglucosidase according to the starch assay kit protocol (Sigma-Aldrich, St. Louis, MO, USA) prior to detection of glucose by HPLC. Undissociated acetic acid levels were calculated from acetate and $\mathrm{pH}$ measurements.

\section{Genome re-sequencing}

Descendants of the ethanologen strain M0355 evolved for improved growth rate and ethanol production via continuous culturing and chemical mutagenesis were sequenced at the National Center for Genome Resources on the Illumina platform, with each strain generating 5 to 8 million $36 \mathrm{bp}$ reads. The reads were assembled onto a draft genome of wildtype T. saccharolyticum reference sequence using SeqMan NGen from DNAStar (Madison, WI, USA). SNPs, and other small mutations were manually verified by examination of the sequence assemblies and distinguished from errors in the draft genome sequence, evident as sequence differences in all strains.

\section{Enzymatic assays}

Cell-free extracts were prepared from cultures grown in $200 \mathrm{~mL}$ TSC7 medium with $10 \mathrm{~g} / \mathrm{L}$ cellobiose at $55^{\circ} \mathrm{C}$ to an optical density of 1.0. Cells were chilled to $4^{\circ} \mathrm{C}$, harvested aerobically by centrifugation at $8,000 \times g$ for $5 \mathrm{~min}$, washed twice with $50-\mathrm{mL}$ cold water, and pelleted to approximately $250-\mathrm{uL}$ wet volume. Cell lysis was performed by addition of B-PER bacterial cell lysis reagent (Thermo Scientific, Rockford, IL, USA) with $0.1 \mathrm{mg}$ lysozyme, $2.5 \mathrm{U}$ DNAse I, and $1 \mathrm{mM}$ phenylmethanesulfonylfluoride per $\mathrm{mL}$ of B-PER reagent. Cell extracts used for acetoacetate decarboxylase assays additionally contained $50 \mathrm{mM}$ dithiothreitol. After cell re-suspension and a 30-min room temperature incubation, cell debris was removed by centrifugation at $15,000 \times g$ for $10 \mathrm{~min}$. Protein concentration was determined via the Bradford method with Bio-Rad Protein Assay Reagent (Bio-Rad, Hercules, CA, USA). All chemicals and enzymes were obtained from Sigma-Aldrich, and reported data are the average of three replicate assays.

Thiolase was assayed in the direction of acetoacetylCoA cleavage, which was monitored at $303 \mathrm{~nm}$ with an extinction coefficient of $14.00 \mathrm{mM}^{-1} \mathrm{~cm}^{-1}$ at room temperature in a Spectramax M2 plate reader (Molecular Devices, Sunnyvale, CA, USA). The assay contained, in a final volume of $200 \mathrm{uL}, 100 \mathrm{mM}$ Tris- $\mathrm{HCl}(\mathrm{pH} 8.0), 1 \mathrm{mM}$ DTT, $10 \mathrm{mM} \mathrm{MgCl}_{2}, 0.05 \mathrm{mM}$ acetoacetyl-CoA, $0.2 \mathrm{mM}$ $\mathrm{CoA}$ and $4 \mu \mathrm{g}$ cell-free extract. Addition of CoA started the reaction, and activity depended on both the presence of acetoacetyl-CoA and cell-free extract. 
CoA-transferase was assayed in the direction of acetate and acetoacetyl-CoA conversion to acetoacetate and acetylCoA. To measure activity, acetyl-CoA was subsequently converted to citrate and CoA via citrate synthase, and CoA formation was monitored with 5,5'-dithiobis-(2-nitrobenzoic acid) (DTNB) at $412 \mathrm{~nm}$ with an extinction coefficient of $14.15 \mathrm{mM}^{-1} \mathrm{~cm}^{-1}$ at room temperature in a Spectramax M2 plate reader. The assay contained, in a final volume of $200 \mathrm{uL}, 67 \mathrm{mM}$ Tris- $\mathrm{HCl}$ (pH 8.0), $10 \mathrm{mM}$ potassium acetate, $1 \mathrm{mM}$ oxaloacetate, $0.1 \mathrm{mM}$ DTNB, 2 U porcine heart citrate synthase, $0.2 \mathrm{mM}$ acetoacetyl-CoA, $0.2 \mathrm{mM} \mathrm{CoA}$, and $4 \mu \mathrm{g}$ cell-free extract. Addition of acetoacetyl-CoA started the reaction, and activity depended on the presence of acetoacetyl-CoA, acetate, and cell-free extract. Control assays without added cell extract were used to subtract baseline signal.

Acetoacetate decarboxylase was assayed in the direction of acetone formation via HPLC with a Fast Acid Analysis column (Bio-Rad, Hercules, CA, USA) with refractive index and UV detection at $260 \mathrm{~nm}$. The assay contained, in a final volume of $1.8 \mathrm{~mL}, 100 \mathrm{mM} \mathrm{KPO}_{4}$ buffer at $\mathrm{pH}$ 6.1, $25 \mathrm{mM}$ lithium acetoacetate and $180 \mu \mathrm{g}$ cell-free extract. The assay began with addition of cell-free extract, and samples were taken at $70 \mathrm{~min}$ and frozen at $-80^{\circ} \mathrm{C}$ until acidification to pH 2 and HPLC analysis. Control assays without added cell extract were used to subtract baseline signal.

\section{Additional file}

Additional file 1: Plasmids and primers used in this study.

\section{Abbreviations}

ADP: adenosine diphosphate; ATP: adenosine triphosphate; CoA: coenzyme A; NADH: nicotinamide adenine dinucleotide; NADPH: nicotinamide adenine dinucleotide phosphate; NMR: nuclear magnetic resonance; RT-PCR: reverse transcriptase-polymerase chain reaction.

\section{Competing interests}

Authors were former employees of Mascoma Corporation, which held a financial interest in intellectual property related to this work.

\section{Authors' contributions}

AJS, WRK, AB, WRS, DAH, and CDH designed experiments and analyzed data. AJS, BBM, SRR, AM, and IS performed experiments. AJS, WRK, and CDH wrote and reviewed the manuscript. All authors have read and approved the final version of this manuscript.

\section{Acknowledgements}

We would like to thank Wayne Casey at the Dartmouth College Department of Chemistry for assistance with NMR analysis. This work was supported by the Mascoma Corporation and the Department of Energy under Award Number DE-FC36-07G017057. Manuscript preparation was supported in part by the BioEnergy Science Center, a U.S. Department of Energy Bioenergy Research Center supported by the Office of Biological and Environmental Research in the DOE Office of Science. Disclaimer This report was prepared as an account of work sponsored by an agency of the United States Government. Neither the United States Government nor any agency thereof, nor any of their employees, makes any warranty, express or implied, or assumes any legal liability or responsibility for the accuracy, completeness, or usefulness of any information, apparatus, product, or process disclosed, or represents that its use would not infringe privately owned rights. Reference herein to any specific commercial product, process, or service by trade name, trademark, manufacturer, or otherwise does not necessarily constitute or imply its endorsement, recommendation, or favoring by the United States Government or any agency thereof. The views and opinions of authors expressed herein do not necessarily state or reflect those of the United States Government or any agency thereof.'

\section{Author details}

'Mascoma Corporation, Lebanon, NH 03766, USA. ${ }^{2}$ Novogy Inc., 85 Bolton St, Cambridge, MA 02140, USA. ${ }^{3}$ Verdezyne Inc., 2715 Loker Avenue West, Carlsbad, CA 92010, USA. "Thayer School of Engineering, Dartmouth College, Hanover, NH 03755, USA. ${ }^{5}$ Energy Biosciences Institute, 2151 Berkeley Way, Berkeley, CA 94704, USA. ${ }^{6}$ Myriant Corporation, 66 Cummings Park, Woburn, MA 01801, USA. ${ }^{7}$ OPX Biotechnologies Inc., 2425 55th Street, Boulder, CO 80301, USA.

Received: 3 March 2015 Accepted: 24 April 2015

Published online: 09 May 2015

\section{References}

1. Perlack RD, Wright LL, Turhollow AF, Graham RL, Stoke BJ, Erbach DC. Biomass as feedstock for a bioenergy and bioproducts industry: the technical feasibility of a billion-ton annual supply. Technical Report. 2005; ORNL/TM-205/66. http://www.osti.gov/scitech/biblio/885984.

2. Palmqvist $E_{1}$ Hahn-Hägerdal B. Fermentation of lignocellulosic hydrolysates. II: inhibitors and mechanisms of inhibition. Bioresource Technol. 2000;74:25-33.

3. Ingram LO, Aldrich HC, Borges AC, Causey TB, Martinez A, Morales F, et al. Enteric bacterial catalysts for fuel ethanol production. Biotechnol Progr. 2009;15:855-66

4. Weil JR, Dien B, Bothast R, Hendrickson R, Mosier NS, Ladisch MR. Removal of fermentation inhibitors formed during pretreatment of biomass by polymeric adsorbents. Ind Eng Chem Res. 2002;41:6132-8.

5. Larsson S, Palmqvist E, Hahn-Hägerdal B, Tengborg C, Stenberg K, Zacchi G, et al. The generation of fermentation inhibitors during dilute acid hydrolysis of softwood. Enzyme Microb Tech. 1999;24:151-9.

6. Ranatunga T, Jervis J, Helm R, McMillan J, Hatzis C. Identification of inhibitory components toxic toward Zymomonas mobilis CP4(pZB5) xylose fermentation. Appl Biochem Biotech. 1997;67:185-98.

7. Sreenath HK, Jeffries TW. Production of ethanol from wood hydrolyzate by yeasts. Bioresource Technol. 2000;72:253-60.

8. Taherzadeh MJ, Niklasson C, Lidén G. Acetic acid - friend or foe in anaerobic batch conversion of glucose to ethanol by Saccharomyces cerevisiae? Chem Eng Sci. 1997;52:2653-9.

9. Lawford H, Rousseau J. Improving fermentation performance of recombinant Zymomonas in acetic acid-containing media. Appl Biochem Biotechnol. 1998;70-72:161-72.

10. Booth IR. Regulation of cytoplasmic pH in bacteria. Microbiol Rev. 1985:49:359-78.

11. Mussatto SI, Roberto IC. Alternatives for detoxification of diluted-acid lignocellulosic hydrolyzates for use in fermentative processes: a review. Bioresource Technol. 2004;93:1-10.

12. Schneider $\mathrm{H}$. Selective removal of acetic acid from hardwood-spent sulfite liquor using a mutant yeast. Enzyme Microb Tech. 1996;19:94-8.

13. Lakshmanaswamy A, Rajaraman E, Eiteman MA, Altman E. Microbial removal of acetate selectively from sugar mixtures. J Ind Microbiol Biot. 2011;38:1477-84.

14. Jones DT, Woods DR. Acetone-butanol fermentation revisited. Microbiol Rev 1986;50:484-524

15. Lütke-Eversloh T, Bahl H. Metabolic engineering of Clostridium acetobutylicum: recent advances to improve butanol production. Curr Opin Biotech. 2011;22:634-47.

16. Shaw AJ, Covalla SF, Hogsett DA, Herring CD. Marker removal system for Thermoanaerobacterium saccharolyticum and development of a markerless ethanologen. Appl Environ Microbiol. 2011;77:2534-6.

17. Shaw AJ, Podkaminer KK, Desai SG, Bardsley JS, Rogers SR, Thorne PG, et al. Metabolic engineering of a thermophilic bacterium to produce ethanol at high yield. Proc Natl Acad Sci U S A. 2008;105:13769-74.

18. Shaw AJ, Hogsett DA, Lynd LR. Identification of the [FeFe]-hydrogenase responsible for hydrogen generation in Thermoanaerobacterium saccharolyticum and demonstration of increased ethanol yield via hydrogenase knockout. J Bacteriol. 2009;191:6457-64. 
19. Wolfe AJ. The acetate switch. Microbiol Mol Biol Rev. 2005;69:12-50.

20. Kumari $S$, Tishel R, Eisenbach M, Wolfe AJ. Cloning, characterization, and functional expression of acs, the gene which encodes acetyl coenzyme A synthetase in Escherichia coli. J Bacteriol. 1995;177:2878-86.

21. Fournier GP, Gogarten JP. Evolution of acetoclastic methanogenesis in Methanosarcina via horizontal gene transfer from cellulolytic clostridia. J Bacteriol. 2008;190:1124-7.

22. Ingram-Smith C, Martin SR, Smith KS. Acetate kinase: not just a bacterial enzyme. Trends Microbiol. 2006;14:249-53.

23. Weimer PJ. Control of product formation during glucose fermentation by Bacillus macerans. J Gen Microbiol. 1984;130:103-11.

24. Freier-Schröder D, Wiegel J, Gottschalk G. Butanol formation by Clostridium thermosaccharolyticum at neutral pH. Biotechnol Lett. 1989;11:831-6.

25. Desai SG, Guerinot ML, Lynd LR. Cloning of L-lactate dehydrogenase and elimination of lactic acid production via gene knockout in Thermoanaerobacterium saccharolyticum JW/SL-YS485. Appl Microbiol Biotechnol. 2004;65:600-5.

26. Ballor N, Paulsen I, Leadbetter J. Genomic analysis reveals multiple [FeFe] hydrogenases and hydrogen sensors encoded by treponemes from the $\mathrm{H}_{2}$-rich termite gut. Microb Ecol. 2012;63:282-94

27. Posewitz MC, Mulder DW, Peters JW. New frontiers in hydrogenase structure and biosynthesis. Curr Chem Biol. 2008:2:178-99.

28. Calusinska M, Happe T, Joris B, Wilmotte A. The surprising diversity of clostridial hydrogenases: a comparative genomic perspective. Microbiol. 2010;156:1575-88.

29. Björkqvist $\mathrm{S}$, Ansell $\mathrm{R}$, Adler L, Lidén G. Physiological response to anaerobicity of glycerol-3-phosphate dehydrogenase mutants of Saccharomyces cerevisiae. Appl Environ Microbiol. 1997;63:128-32.

30. Van Dijken JP, Scheffers WA. Redox balances in the metabolism of sugars by yeasts. FEMS Microbiol Lett. 1986:32:199-224.

31. Ansell R, Granath $\mathrm{K}$, Hohmann S, Thevelein JM, Adler L. The two isoenzymes for yeast NAD +-dependent glycerol 3-phosphate dehydrogenase encoded by GPD1 and GPD2 have distinct roles in osmoadaptation and redox regulation. EMBO J. 1997;16:2179-87.

32. Brown SD, Guss AM, Karpinets TV, Parks JM, Smolin N, Yang S, et al. Mutant alcohol dehydrogenase leads to improved ethanol tolerance in Clostridium thermocellum. Proc Natl Acad Sci U S A. 2011:108:13752-7.

33. Mariano AP, Dias MOS, Junqueira TL, Cunha MP, Bonomi A, Filho RM. Butanol production in a first-generation Brazilian sugarcane biorefinery: technical aspects and economics of greenfield projects. Bioresource Technol. 2013;135:316-23.

34. Acetone uses and market data. Technical Report. Independent Commodity Information Services; ICIS News. 2007 09:34, updated 2010.

35. Aden A, Ruth M, Ibsen K, Jechura J, Neeves K, Sheehan J, et al. Lignocellulosic biomass to ethanol process design and economics utilizing co-current dilute acid prehydrolysis and enzymatic hydrolysis for corn stover. Technical Report. 2002; NREL/TP-510-32438, NREL, Golden, CO. http://www.osti.gov/scitech/biblio/15001119.

36. Shanks RMQ, Kadouri DE, MacEachran DP, OToole GA. New yeast recombineering tools for bacteria. Plasmid. 2009;62:88-97.

37. Shaw AJ, Hogsett DA, Lynd LR. Natural competence in Thermoanaerobacter and Thermoanaerobacterium species. Appl Environ Microbiol. 2010;76:4713-9.

\section{Submit your next manuscript to BioMed Central and take full advantage of:}

- Convenient online submission

- Thorough peer review

- No space constraints or color figure charges

- Immediate publication on acceptance

- Inclusion in PubMed, CAS, Scopus and Google Scholar

- Research which is freely available for redistribution 